\title{
Structure and activity of putative intronic miRNA promoters
}

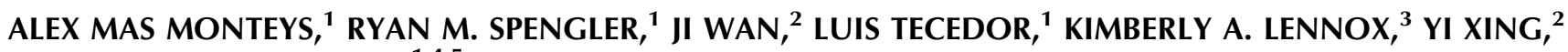 \\ and BEVERLY L. DAVIDSON ${ }^{1,4,5}$ \\ ${ }^{1}$ Department of Internal Medicine, University of lowa, lowa City, lowa 52242, USA \\ ${ }^{2}$ Department of Biomedical Engineering, University of lowa, lowa City, lowa 52242, USA \\ ${ }^{3}$ Integrated DNA Technologies, Coralville, lowa 52246, USA \\ ${ }^{4}$ Department of Molecular Physiology and Biophysics, University of lowa, lowa City, lowa 52242, USA \\ ${ }^{5}$ Department of Neurology, University of lowa, lowa City, lowa 52242, USA
}

\begin{abstract}
MicroRNAs (miRNAs) are RNA sequences of $\sim 22$ nucleotides that mediate post-transcriptional regulation of specific mRNAs. miRNA sequences are dispersed throughout the genome and are classified as intergenic (between genes) or intronic (embedded into a gene). Intergenic miRNAs are expressed by their own promoter, and until recently, it was supposed that intronic miRNAs are transcribed from their host gene. Here, we performed a genomic analysis of currently known intronic miRNA regions and observed that $\sim 35 \%$ of intronic miRNAs have upstream regulatory elements consistent with promoter function. Among all intronic miRNAs, $30 \%$ have associated Pol II regulatory elements, including transcription start sites, CpG islands, expression sequence tags, and conserved transcription factor binding sites, while $5 \%$ contain RNA Pol III regulatory elements (A/B box sequences). We cloned intronic regions encompassing miRNAs and their upstream Pol II (miR-107, miR-126, miR-208b, miR548f-2, miR-569, and miR-590) or Pol III (miR-566 and miR-128-2) sequences into a promoterless plasmid, and confirmed that miRNA expression occurs independent of host gene transcription. For miR-128-2, a miRNA overexpressed in acute lymphoblastic leukemia, ChIP analysis suggests dual regulation by both intronic (Pol III) and host gene (Pol II) promoters. These data support complex regulation of intronic miRNA expression, and have relevance to disregulation in disease settings.
\end{abstract}

Keywords: Pol II; Pol III; intronic; microRNA promoters

\section{INTRODUCTION}

MicroRNAs (miRNAs) are small RNA sequences of $\sim 22$ nucleotide (nt) length that generally inhibit gene expression through interactions with the $3^{\prime}$ UTR of target mRNAs (Lai 2002; Bagga et al. 2005). miRNAs are disseminated throughout the genome and are either set between independent transcription units (intergenic) or found in the intronic sequences of protein-coding genes or in intronic or exonic regions of noncoding RNAs (intronic). Recent reports have shown that $\sim 50 \%$ of vertebrate miRNAs are intronic (Griffiths-Jones 2007; Saini et al. 2008). While intergenic miRNAs genes have their own transcription regulatory elements, including promoters and terminator signals, until

Reprint requests to: Beverly L. Davidson, Department of Internal Medicine, 200 Eckstein Medical Research Building, University of Iowa, Iowa City, IA 52242, USA; e-mail: beverly-davidson@uiowa.edu, fax: (319) 353-3372.

Article published online ahead of print. Article and publication date are at http://www.rnajournal.org/cgi/doi/10.1261/rna.1731910. very recently it was generally accepted that intronic miRNAs are expressed from the host gene promoter (Pol II) and require RNA splicing machinery. Two different mechanisms have been described for processing of intronic miRNAs from the host gene primary transcript. In one, Drosha-mediated processing occurs after transcript incorporation into the spliceosome complex, but before intron excision. Primary miRNAs (pri-miRNAs) and Drosha colocalization to transcription sites, along with pri-miRNA enrichment in the chromatin-associated nuclear fraction, supports simultaneous transcription and processing of miRNA sequences (Lee et al. 2002, 2003; Kim and Kim 2007; Morlando et al. 2008; Pawlicki and Steitz 2008). After Drosha cleavage, precursor miRNA (pre-miRNA) sequences are exported to the cytoplasm by Exportin-5 (Bohnsack et al. 2004; Lund et al. 2004), processed by Dicer into mature miRNAs, and incorporated into the RNA-induced silencing complex (RISC) (Bernstein et al. 2001; Hutvagner et al. 2001; Gregory et al. 2005). Other reports show that intronic miRNAs residing in short introns (Mirtrons) (Berezikov et al. 2007) 
are exported directly to the cytoplasm after splicing, followed by Dicer cleavage. Mirtrons, therefore, bypass the initial Drosha/DGCR8 processing (Okamura et al. 2007; Ruby et al. 2007). Some Mirtrons contain extended $5^{\prime}$ or $3^{\prime}$ tail ends, which require trimming for efficient nuclear export, presumably by exonucleases distinct from Drosha.

If processing from the host gene primary transcript is the sole pathway for intronic miRNA generation, then the miRNA and host gene expression should be highly correlative. However, recent studies indicate many instances of poor correlation (Baskerville and Bartel 2005; Liang et al. 2007). A case in point is miR-128-2. Mi et al. (2007) report that the intronic miRNA miR-128-2, which is embedded in an intron of $A R P P 21$, is significantly overexpressed in patients with acute lymphoblastic leukemia (ALL), but not in acute myeloid leukemia. Interestingly, elevated miR-128-2 levels were not due to increased gene copy number or ARPP21 promoter hypomethylation (Mi et al. 2007). Several possible mechanisms could explain discordant expression between a miRNA and its host gene, including disparate transcript stabilities, post-transcriptional miRNA regulation, or host-gene-independent expression of intronic miRNAs. In this study, we sought to test the latter possibility.

Mapping intergenic miRNA promoters is based on identifying known common DNA features including CpG islands, transcription start sites (TSS), conserved transcription factor binding sites (TFBS), poly(A) signals, and EST data in the regions surrounding the miRNA sequences (Saini et al. 2007; Zhou et al. 2007; Fujita and Iba 2008). Recent work in different cell lines predicted miRNA promoters by combining bioinformatic analysis of DNA features with ChIP-on-chip screens for histone modifications (Wang et al. 2009) or combining nucleosome positioning patterns with ChIP-on-chip screens for promoter signatures (Ozsolak et al. 2008). These studies characterized new intergenic miRNA promoters, and as well, identified several intronic promoters upstream of intronic miRNAs.

Because such approaches are limited to the discovery of promoters active in the cell lines under study, in the current investigation we took an approach that includes all known intronic miRNAs in the miRbase database (Griffiths-Jones et al. 2008). We found that $\sim 35 \%$ of intronic miRNAs have predicted promoters. This is based on the presence of nearby upstream DNA regulatory elements common to Pol II promoters (CpG islands, TSS, and TFBS) and association with known ESTs, or the presence of RNA Pol III regulatory sequences (A/B boxes). We cloned several intronic miRNAs and 5 '-flanking sequences bearing putative regulatory elements into promoterless plasmids and confirmed promoter activity. In addition, using ChIP analysis and inducers of resident gene transcription, we provide evidence that miR128-2 can be transcribed both dependently and independently of its host gene promoter. Finally, we identify Hip-1, a protein overexpressed in many primary tumors and involved in apoptosis, as a target of miR-128-2.

\section{RESULTS}

\section{Predictive analysis of intronic miRNA promoters}

The poor correlation of expression level observed with several intronic miRNAs and their respective host genes incited us to investigate a molecular mechanism that could be responsible. One feasible explanation is that in addition to the host gene promoter, intronic miRNAs might have their own transcriptional regulatory elements for independent expression from the intron. We performed a genomic analysis of 253 intronic miRNAs obtained from miRBase 12.0 database (Griffiths-Jones et al. 2008) to predict intronic promoters (Table 1; Supplemental Table 1). As an initial approach to predict Pol II promoters, we used the Switchgear genomics database and the Eponine method (Down and Hubbard 2002) in the UCSC genome browser to identify putative TSS. Although there is evidence of promoter activity far upstream of intergenic miRNAs, for intronic miRNAs we limited our search to consider putative TSS that were located within $5 \mathrm{~Kb}$ upstream of the intronic miRNA sequences. Using this criterion, we found that $\sim 30 \%$ of intronic miRNAs contain a TSS in close proximity (76 of 253 intronic miRNAs) (Supplemental Table 2). The mean distance between the predicted TSS and the intronic miRNA sequence was $2 \mathrm{~Kb}$. Distribution analysis of TSS localization with respect to the pre-miRNA sequence showed that $\sim 57 \%$ of predicted TSS were located within $0-2 \mathrm{~Kb}, \sim 33 \%$ within $2-4 \mathrm{~Kb}$, and $\sim 10 \%$ between 4 and $5 \mathrm{~Kb}$. In some cases multiple predicted TSS were found. Next, we determined if the predicted TSS were associated with known EST sequences. We found $78 \%$ of predicted TSS to be located at the $5^{\prime}$ end of validated ESTs (Supplemental Table 2). These results support the existence of intronic promoters and transcription from them.

The proximity of CpG islands to predicted TSS was the second DNA feature considered for mapping Pol II intronic promoters (Supplemental Table 3). It is known that CpG islands are located near TSS in $\sim 40 \%$ of human promoters and have a role in regulation of gene expression (Larsen et al. 1992; Lujambio and Esteller 2007). We found that 39\% of predicted TSS near the intronic miRNAs also contained a CpG island within a range of $4 \mathrm{~Kb}$ (30 of 76 predicted TSS) (Supplemental Table 3 ). For $\sim 53 \%$ of these (16 of 30 ) the CpG islands overlapped with the predicted TSS.

We next searched for conserved TFBSs, motifs within 1.5 $\mathrm{Kb}$ upstream of or downstream from putative TSS. In total, $68 \%$ of intronic miRNAs with a putative TSS contain TFBS sequences near their TSS (52 of 76) (Supplemental Table 4 ). Overall, we observed that $\sim 80 \%$ of the predicted TSSs are also associated with a CpG island and/or a TFBS, whereas the remaining $20 \%$ are at least associated with validated EST sequences. Together, these features strongly indicate that a significant proportion of intronic miRNAs have resident Pol II promoters. 
TABLE 1. Survey of intronic miRNA promoters ${ }^{\mathrm{a}}$

Number Percentage

\begin{tabular}{lrc} 
Intronic miRNAs (Sanger 12.0 release) & 253 & 100 \\
Intronic miRNAs with predicted promoters $^{\text {Pol II TSS }}$ & 89 & 35 \\
Po $^{\mathrm{b}}$ & 76 & 30 \\
Close to CpG island $^{\mathrm{c}}$ & 30 & $39^{\mathrm{c}}$ \\
Close to conserved TFBS $^{\mathrm{c}}$ & 52 & $68^{\mathrm{c}}$ \\
Pol III A/B boxes $^{\mathrm{b}}$ & 13 & 5 \\
Associated with transposable elements $^{\mathrm{d}}$ & 4 & $30^{\mathrm{d}}$ \\
\hline
\end{tabular}

${ }^{\mathrm{a}}$ The UCSC genome browser was used for evaluation of a $5-\mathrm{kb}$ region upstream of the annotated miRNA sequence.

${ }^{b}$ Predicted A-box and B-box sequences were obtained from Pol3scan. (http://wwwmgs.bionet.nsc.ru/mgs/programs/poliiiscan/) (Naykova et al. 2003). A genomic region flanked by Pol III stop signals upstream of and downstream from the intronic miRNA, and devoid of Pol II regulatory elements, were aligned to the A-box and B-box data set using seqmap (Jiang and Wong 2008).

${ }^{c}$ Relative to all Pol II predicted promoter with TSSs found $\leq 5 \mathrm{~kb}$ of miRNA sequence.

${ }^{\mathrm{d}}$ Relative to intronic miRNAs with predicted Pol III A/B boxes.

We next assessed whether predicted Pol III promoter elements were present in the vicinity of the remaining intronic miRNAs. Two different strategies were used. First, a data set of A-box and B-box regulatory sequences of known tRNA genes (Pol3scan) (Naykova et al. 2003) was used to map putative Pol III regulatory sequences with the Seqmap program (Jiang and Wong 2008). Second, an additional search was done by using the consensus A-box (TRGCNNARYNGG) and B-box (GGTTCRANNCC) sequences (Geiduschek and Tocchini-Valentini 1988). Using these criteria and the programs described above, we found 13 intronic miRNAs with nearby sequences with high similarity to known A-box and B-boxes (Supplemental Fig. 1; Supplemental Tables 5, 6). In all 13 cases, the miRNA sequence was located downstream from at least one A box (sometimes with partial overlap) and B boxes were located $5^{\prime}$ or $3^{\prime}$ from the miRNA. In two instances (hsa-miR-591 and hsa-miR-643) a 4-T stretch was located upstream of the pre-miRNA sequence. RNA Pol III generally terminates transcription at a run of four or more thymidine (T) residues. Of note, the sequence context of 4 -T's can influence its recognition as a Pol III terminator (Bogenhagen and Brown 1981; Gunnery et al. 1999). For instance, in the case of tRNA-Leu and tRNA-Lys (accession nos. M55690 and U00939.1, respectively) internal 4-T stretches are not recognized as terminators. This is also the case for some artificial shRNA transcripts (Grimm et al. 2006). For four of 13 promoters identified, the miRNAs were embedded within SINE transposable elements (Alu or MIR mobile elements) (Supplemental Fig. 1; Supplemental Tables 5, 6). Overall, our analysis predicts that 35\% of intronic miRNAs (89/253) (Table 1; Supplemental Table 1) have associated Pol II or Pol III promoters that could drive transcription independently of the host gene promoter.

\section{Experimental validation of predicted intronic promoters}

Next, we experimentally tested several of the predicted Pol II and Pol III promoters for their ability to drive miRNA expression (Fig. 1A-F). The predicted intron-resident Pol II promoters along with the downstream miRNA sequences of miR-107, miR-126, miR-208b, miR-548f-2, miR-569,

A

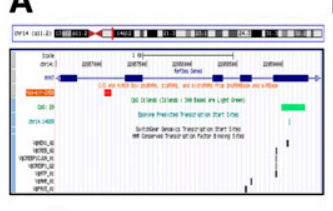

B

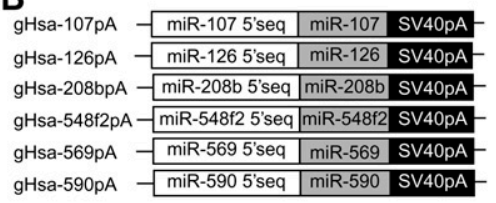

C $\frac{m i R-107}{N T C \text { RT+RT- }} \frac{m i R-126}{\text { NTC RT+RT- }} \frac{m i R-208 \mathrm{~b}}{\text { NTC RT+RT- NTC RT+RT- }} \frac{m i R-548 f 2}{\text { NTC RT+RT- NTC RT+RT- }}$

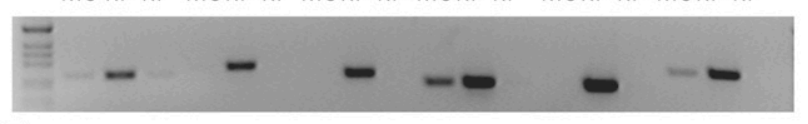

D

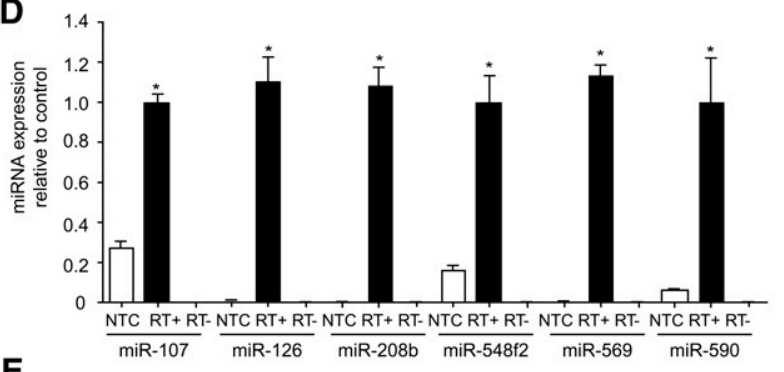

E
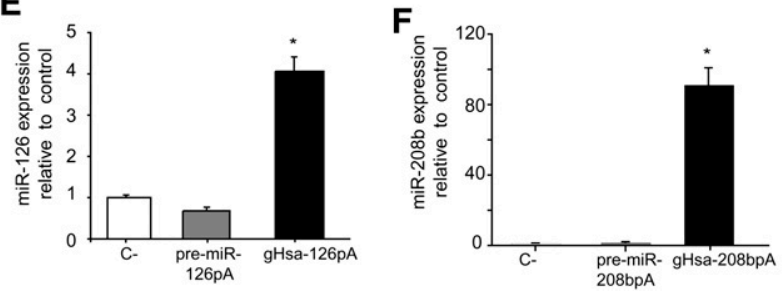

FIGURE 1. Pol II intronic promoters drive intronic miRNA expression. (A) Representative diagram of the predicted Pol II intronic promoter of miR-208b. (B) Diagrams of vectors to determine functionality of Pol II intronic promoters. A genomic fragment containing the predicted promoter of miR-107, miR-206, miR-208b, miR-548f-2, miR-569, or miR-590, followed by the miRNA sequence, was cloned into a promoterless plasmid with a poly $(\mathrm{A})$ signal. $(C, D)$ Predicted intronic Pol II promoters transcribe intronic miRNAs. HEK293 cells were transfected with the constructs depicted. Active transcription from intronic promoters was detected on RNA harvested from cell lysates by RT-PCR $(C)$ and by SYBR-green RT-qPCR $(D)$ in the presence of Reverse Transcriptase $(\mathrm{RT}+)$. Nontransfected control (NTC) cells and no RT (RT-) reactions were used as controls. Relative pre-miRNA levels were normalized to $\beta$-actin. Data are mean \pm SEM. $\left.{ }^{*}\right) P<0.05, n=4$. (E,F) HEK293 cells were transfected with plasmids containing pre-miRNA sequence with or without the predicted promoter sequence. Expression of miR-126 (E) and miR$208 \mathrm{~b}(F)$ was determined by qPCR and was found to be significantly higher than control (endogenous) levels only in RNA obtained from cells transfected with plasmids containing the predicted promoter. Mature miRNA expression was normalized to RNU48 expression and compared with nontransfected controls. Data are mean \pm SEM. $\left({ }^{*}\right)$ $P<0.05 ; n=4$. 
and miR-590 were cloned into a promoterless plasmid containing a poly(A) signal (Fig. 1B). Expression of the miRNAs was measured initially by reverse transcription polymerase chain reaction (RT-PCR) following transfection into HEK293 cells. Expression of all tested miRNAs was detected in transfected $(\mathrm{RT}+$ ) (Fig. 1C) relative to nontransfected (NTC) or no-RT controls (RT-). For some miRNAs, faint bands were detected by RT-PCR in nontransfected controls, corresponding to endogenous expression in HEK293 cells (Fig. 1C). Quantitation of expression by quantitative polymerase chain reaction (qPCR) shows that the intronic fragments flanking miR-107, 126, 208b, $548 \mathrm{f}-2,569$, and 590 significantly increase levels of mature miRNAs relative to controls (Fig. 1D).

We subsequently cloned only the pre-miRNA sequence of miR-126 and miR-208b, followed by a poly(A) signal into the promoterless plasmid to negate the possibility of a cryptic promoter within the vector. HEK293 cells were transfected with plasmids containing only the pre-miRNA (pre-miR-126pA and pre-miR-208bpA), or the pre-miRNA plus the predicted promoter sequence (gHsa-126pA and gHsa-208bpA), and miRNA expression was determined by qPCR (Fig. 1E,F). qPCR data show that mature miRNA levels are significantly increased relative to nontransfected cells ( 90 fold: miR208b, fourfold: miR-126), and that miR126 and miR-208b expression was not elevated in cells transfected with plasmids containing only the pre-miRNA sequences (Fig. 1E,F). The data demonstrate that the predicted Pol II promoters are functional in their ability to independently drive transcription of intronic miRNAs when removed from the context of their host gene.

Mir-566 is an intronic miRNA located in the second intron of the human semaphorin $3 \mathrm{~F}$ gene (SEMA3F) and our analysis predicts that miR-566 could be Pol III transcribed (Supplemental Fig. 1; Supplemental Tables 5, 6). Interestingly, miR-566 is also embedded within a primatespecific Alu retrotransposon (Fig. 2A). To assess whether the predicted Pol III promoter could drive miR-566 expression, we cloned a 1.2-kb fragment of the second intron of the human SEMA3F gene, encompassing miR-566 and the upstream sequences containing the Pol III regulatory sequences, into a promoterless plasmid (Fig. 2B). The equivalent intronic sequence of mouse $\operatorname{Sem} A 3 f$, devoid of Alu sequences and the embedded miR-566 (Fig. 2A), was also cloned into the promoterless plasmid (Fig. 2B) and served as a negative control. We noted a 68 -fold increase in miR-566 expression relative to the negative control as detected by RTqPCR after transfection into HEK293 cells (Fig. 2C). To assess if miR-566 expression can occur in vivo independent of its host gene, we measured Sema3F and miR-566 expression in peripheral blood mononuclear cells (PBMCs), a tissue that lacks Sema3F expression (Sekido et al. 1996). By RT-qPCR, we did not detect Sema3F expression in PBMCs, while miR-566 was clearly present (Fig. 2D). Our results suggest that miR-566 expression may occur from the intronic promoter in vivo, and based on our in vitro studies, may arise independent of host gene transcription.

A recent report demonstrated miR-128-2 overexpression in acute lymphoblastic leukemia (ALL), a common childhood cancer (Mi et al. 2007). Interestingly, the investigators noted that miR-128-2 overexpression was not exclusively due to increased expression of its host gene (ARPP-21). One possible explanation is that miR-128-2 transcription can occur from intronic promoter activity. Sequences upstream of pre-miR-128-2 harbor predicted A-box and B-box regulatory sequences (Supplemental Tables 5, 6), with a putative Pol III terminator (5 T's) located 304-nt downstream (Supplemental Fig. 1). To experimentally validate that miR-128-2 could be expressed from the upstream intronic region, we cloned miR-128-2 and flanking sequences into a promoterless plasmid, followed by a synthetic Pol III terminator signal (Fig. 2E, gHsa-128-2). After transfection of HEK293 cells and RT-qPCR analysis, we found a 10 -fold increase in miR-128-2 expression from the gHsa-miR-128-2 plasmid compared with transfection with a control vector (U6-miGFP), confirming promoter activity upstream of miR-128-2 (Fig. 2F).

We further tested the 5 '-flanking region of miR-128-2 for its ability to drive transcription of a heterologous small RNA. As a readout, we used knockdown of luciferase in the
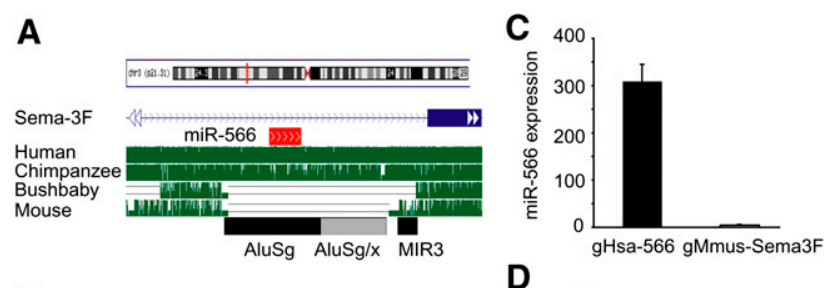

B

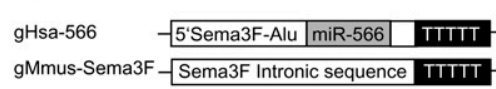

E

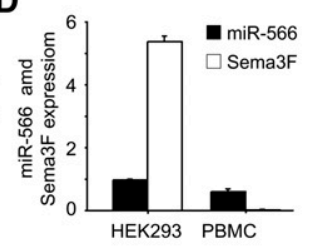

gHsa-128-2
U6-miGFP
miR128-2-5'-HD2.1
U6-miR-128-2
U6-miHD2.1
PS-HD2.1

$\mathbf{F}$

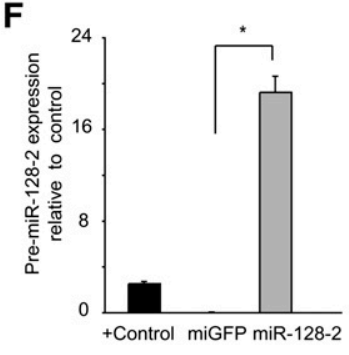

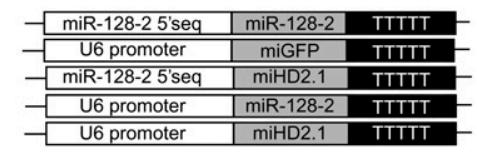

-HSV-TKP

G

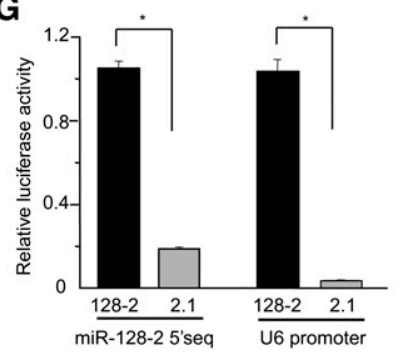

FIGURE 2. (Legend on next page) 
psiCHECK-2 reporter system. For this, an artificial miRNA previously designed to silence huntingtin (Boudreau et al. 2008) was cloned downstream from the putative miR-128-2 promoter (Fig. 2E, miR-128-2-5'-HD2.1). A psiCHECK-2 reporter consisting of a target sequence for miHD2.1 cloned into the 3'UTR of Renilla luciferase was used to assess silencing activity (Fig. 2E, PS-HD2.1). Expression plasmids with the U6 promoter driving miHD2.1 (Fig. 2E, U6 miHD2.1) or miR-128-2 (Fig. 2E, U6 miR-128-2) were used as positive or negative controls, respectively. As expected, cotransfection of the positive control plasmid U6miHD2.1 with PS-HD2.1 reporter caused efficient luciferase knockdown (90\%) compared with negative controls. Cotransfection of miR-128-2-5'HD2.1 with PSHD2.1 diminished Renilla luciferase activity by $\sim 80 \%$ (Fig. 2G), nearly as effective as the positive control. Together, the data show that the $5^{\prime}$-flanking region of miR-128-2 has promoter activity and may permit independent expression of the intronic miRNA.

FIGURE 2. Pol III intronic promoters drive intronic miRNA expression. (A) Representative diagram of the miR-566 genomic locus in several species. (B) Diagram of gHsa-miR-566 and gMmus-Sema3F constructs. The gHsa-miR-566 construct contains the intronic sequence of SEMA3F harboring the primate-specific Alu-derived miR566 sequence. gMmus-Sema3F construct contains the equivalent intronic sequence of Sema3F from mouse, which is devoid of intronic miRNA sequence. (C) Mir-566 expression in HEK293 cells. Mir-566 expression was detected by qPCR in HEK293 cells after transfection with gHsa-566, but not in cells transfected with gMmus-Sema3F. MiR-566 levels were normalized to $18 \mathrm{~S}$ expression and compared with cells transfected with gMmus-Sema3F. Data are mean \pm SEM. $\left.{ }^{*}\right) P<$ $0.05, n=4$. (D) Mir-566 is expressed independently of Sema3F. MiR566 and Sema3F expression were determined in HEK293 cells and PBMC cells. Data show expression of both miR-566 and Sema3F in HEK293 cells, while PBMC cells express only miR-566 and not the host gene. MiR-566 and Sema3F levels were normalized to $18 \mathrm{~S}$ expression. Data are mean \pm SEM. $\left(^{*}\right) P<0.05, n=4$. $(E-G)$ An intronic Pol III promoter expresses miR-128-2. (E) Diagrams of miRNA expression vectors and the Renilla luciferase reporter for assessing promoter activity of the $5^{\prime}$ sequence of miR-128-2. gHsa128-2 corresponds to a genomic fragment containing pre-miR-128-2 and its upstream sequence. U6-miGFP, U6-miHD2.1, and U6-miR128-2 are Pol III expression vectors with the U6 promoter driving miGFP, miHD2.1, or pre-miR-128-2 sequences. MiR-128-2-5'HD2.1 contains the upstream sequence of miR-128-2 as a putative promoter sequence upstream of miHD2.1. PS-HD2.1 is the Renilla luciferase reporter plasmid to test for functional miHD2.1 liberated from U6-miHD2.1 (positive control) or miR-128-2-5'-HD2.1. HSV-TKP, herpes simplex virus thymidine kinase promoter; SV40p, simian virus 40 promoter; FF Luc, Firefly luciferase; Ren Luc, Renilla luciferase; 2.1 corresponds to the target sequence of miR-HD2.1; pA, polyA; TTTTT, Pol III stop signal. $(F)$ The predicted intronic Pol III promoter expresses miR-128-2. Data show expression of pre-miR-128-2 in HEK293 cells after transfection relative to cells transfected with negative control plasmid (U6-miGFP). RNA from striatum was used as a positive control (+Control). Pre-miR-128-2 levels were normalized to $18 \mathrm{~S}$ expression. Data are mean \pm SEM. $\left({ }^{*}\right) P<0.05, n=4 .(G)$ The upstream sequence of miR-128-2 drives expression of miHD2.1. Luciferase assays of lysates harvested after cotransfection of PS-HD2.1 and U6-miHD2.1, U6-miR-128-2, gHsa-128-2, or miR-128-2-5'HD 2.1. Data represent mean \pm SEM. $\left.{ }^{*}\right) P<0.05, n=4$.
To confirm that the miR-128-2 promoter lacks Pol II activity, we developed an eGFP reporter system. This system takes advantage of the ability of Pol II, but not Pol III, to read through an extended poly- $\mathrm{T}$ stretch. HEK293 cells were transfected with a known Pol II promoter reporter (CMVeGFP), known Pol III promoter reporters (U6eGFP or pALeGFP) (Borchert et al. 2006), or the miR-128-2 promoter reporter (miR-128-2-5'eGFP), wherein a poly- $\mathrm{T}$ stretch is positioned between a spacer sequence of $48 \mathrm{nt}$ and the eGFP sequence (Fig. 3A). eGFP expression was determined $36 \mathrm{~h}$ later. As expected, strong eGFP expression was observed by fluorescence microscopy in cells transfected with CMVeGFP, reflecting the ability of Pol II to read through the poly-T and transcribe eGFP (Fig. 3B). We observed significantly reduced, but detectable eGFP expression on HEK293 cells transfected with U6eGFP, despite the fact that U6 is widely considered strictly as a Pol III promoter. However, this result is consistent with prior studies demonstrating basal Pol II transcription activity associated with the U6 promoter in transfected cells (Park and Kunkel 1995). As expected, no eGFP fluorescence was detected in cells transfected with pALeGFP. In cells transfected with miR-128-2-5'eGFP, eGFP expression was also undetectable, indicating that the $5^{\prime}$-flanking region of miR-128-2 does not support Pol II activity. Western blot evaluation of eGFP in cell lysates was consistent with the microscopy findings (Fig. 3C), as was RT-PCR assessment for Pol II-derived transcripts (Fig. 3D). Together with the bioinformatics and luciferase knockdown studies, the data provide evidence for Pol III, but not Pol II, transcription of miR-128-2 from an intron-resident promoter. Recent work published while these studies were in progress are consistent with our results; Ozsolak et al. (2008) showed that miR-128-2 expression was $\alpha$-amanitin insensitive at doses that inhibit Pol II, and they showed by ChIP that the promoter was occupied by Pol III.

To confirm that occupancy of RNA Pol III within the intron of the miR-128-2 gene occurs in vivo, we performed a ChIP on CRL-1873 cells. This cell line was obtained from the bone marrow of a patient with ALL, and expresses miR-128-2 (data not shown). Specific antibodies against RNA type II and RNA type III polymerases were used for ChIP, and enrichment of the intronic region of miR-128-2 was assessed by qPCR. PCR-specific primers for U6/1 snRNA (Pol III transcribed) and U2 snRNA (Pol II transcribed) genes were used as controls. Accordingly, enrichment of the U6 snRNA was observed after immunoprecipitation (IP) with the Pol III antibody, and enrichment of U2 snRNA was observed after IP with Pol II antibody, not vice versa (Fig. 4A), demonstrating the fidelity of our methods.

Interestingly, the ChIP analysis showed enrichment of miR128-2 after IP with Pol II (fivefold) or Pol III (sevenfold) antibodies (Fig. 4B), indicating that miR-128-2 could be generated in vivo from transcripts arising from Pol II and 
A

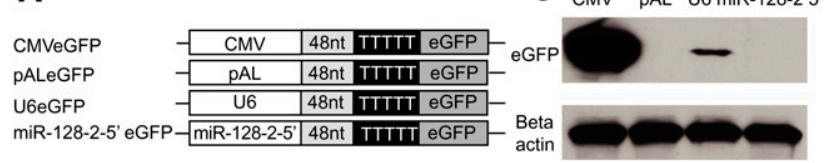

\section{B}
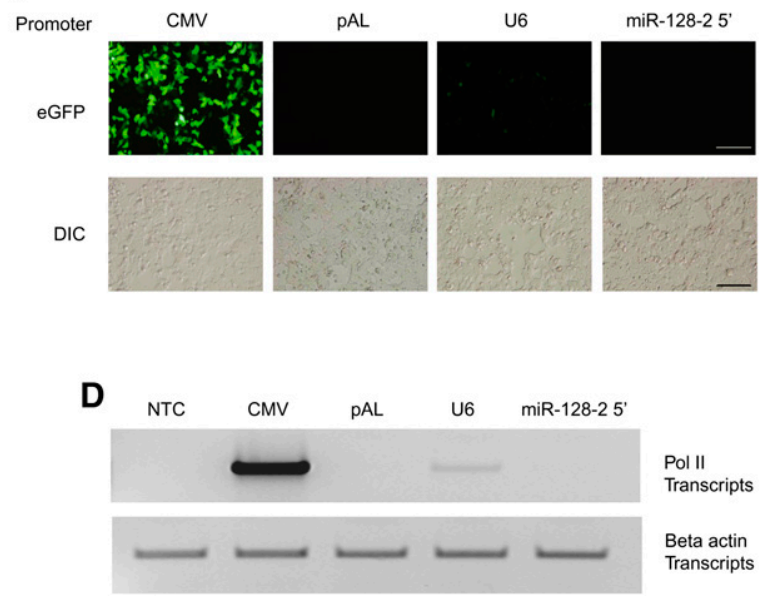

FIGURE 3. Characterization of the intronic miR-128-2 promoter by an eGFP reporter system. (A) Diagram of the eGFP-reporter constructs to differentiate Pol II and Pol III transcription. CMVeGFP contains a CMV promoter ( $\mathrm{Pol}$ II), followed by a spacer sequence, a Pol III terminator signal, an eGFP cDNA, and a SV40pA signal. U6eGFP, pALeGFP, and miR-128-2 5' eGFP refer to constructs harboring a U6 promoter, a Pol III Alu-derived promoter or the $5^{\prime}$ sequence of miR-128-2, respectively. (B) eGFP expression in HEK293 cells transfected with the eGFP-promoter reporter constructs. Scale bar, $200 \mu \mathrm{m}$. (C) Representative Western blot for eGFP indicates robust expression of eGFP in CMVeGFP-transfected cells, modest but detectable expression in U6eGFP-transfected cells, and no detectable eGFP expression in cells transfected with miR-128-2 5'eGFP or pALeGFP. $\beta$-actin was used as a protein-loading control. (D) RTPCR to assess Pol III versus II transcription. HEK293 cells were transfected with the eGFP promoter-reporter constructs and RNA assayed by RT-PCR. The expected 500-bp amplicon was seen in cells transfected with CMVeGFP and U6eGFP, confirming Pol II transcription. No amplicon was observed in cells transfected with pALeGFP or miR-128-2 5'eGFP.

Pol III. Since miR-128-2 is localized in the intronic sequence of Arpp-21 (Fig. 4C), we tested if miR-128-2 expression corresponds with host gene expression. Mouse Arpp-21 is BDNF inducible (Ivkovic and Ehrlich 1999). When BDNF was added to cells expressing endogenous Arpp-21, we noted a $60 \%$ increase in Arpp-21 expression and a similar increase in premiR-128-2 expression (Fig. 4D). Together with prior work in ALL (Mi et al. 2007), the data indicate that miR-128-2 expression may be regulated by the Pol III intronic-resident promoter or the host gene promoter.

Canonical Pol III type 2 promoters have an A-box and B-box sequence with various spacing (Geiduschek and Tocchini-Valentini 1988). Prior ChIP and $\alpha$-amanitin data (Ozsolak et al. 2008) and the experiments in Figures 2-4 strongly suggest Pol III promoter activity driving miR-128-2.

Because the A-box and B-box elements upstream of miR128-2 are consistent with but not identical to consensus motifs (Supplemental Fig. 1; Supplemental Tables 5, 6; Geiduschek and Tocchini-Valentini 1988; Gaeta et al. 1990), deletions and mutations were made to assess their functional relevance. First, miR-128-2 promoter activity was examined by gross deletion of sequences upstream of the putative regulatory elements (Supplemental Fig. 2A). RT-qPCR analysis for pre-miR-128-2 levels after transfection to HEK293 cells revealed a modest but significant reduction of pre-miR-128-2 expression when the region immediate to the A-box and B-box was removed (shInt-1) (Supplemental Fig. 2A,B), and substantial reduction when the entire promoter region (shInt-2) (Supplemental Fig. 2A,B) was removed. Site-directed mutagenesis has been used previously to determine nucleotides essential for Pol III promoter function (Stewart et al. 1985; Gaeta et al. 1990; Lee et al. 1991). Nucleotide substitutions were introduced into the predicted A-box and B-box elements as indicated (Supplemental Fig. $2 \mathrm{C}$ ) and promoter activity assessed by measuring pre-miR128-2 (Supplemental Fig. 2D) and mature miR-128-2

A

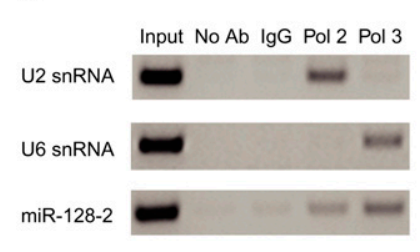

\section{C} Arpp-21/miR-128-2
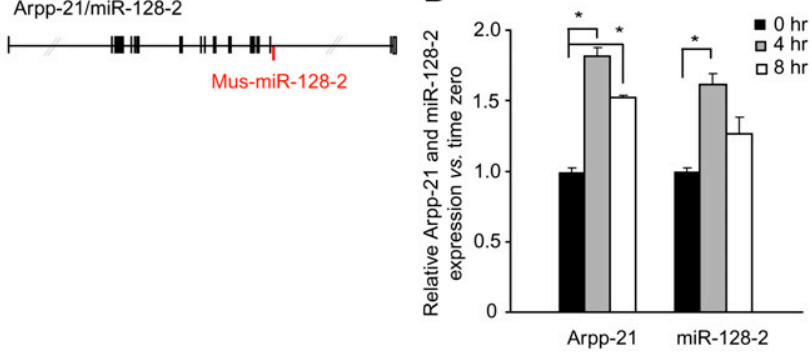

FIGURE 4. Analysis of endogenous miR-128-2 promoter activity. $(A, B)$ ChIP from ALL cells to ascertain Pol II and Pol III occupancy upstream of miR-128-2. (A) Representative PCR showing enrichment of miR-128-2 intronic sequence after ChIP with Pol II or Pol III antibodies. U6 snRNA (Pol III control) and U2 snRNA (Pol II control) are also shown. (B) Quantitation of ChIP data. Data are mean \pm SEM relative to no-antibody control $(n=3)$. (C) Diagram showing localization of miR-128-2 within the intronic sequence of its host gene Arpp-21. (D) qPCR analysis of pre-miR-128-2 expression and its host gene in response to BDNF induction $(50 \mathrm{ng} / \mathrm{mL})$ in primary cortical neuronal cultures. Results demonstrate miR-128-2 and Arpp-21 expression increases after BDNF treatment. RNA levels of pre-miR-128-2 and Arpp-21 were normalized to $\beta$-catenin expression. Data are mean \pm SEM relative to samples collected before BDNF treatment. $\left.{ }^{*}\right) P<0.05$; Student $t$-test, $n=5$ samples each time point. 
(Supplemental Fig. 2E) levels after transfection of the expression plasmids into HEK293 cells. Pre-miR-128-2 and mature miR-128 expression was reduced on cells transfected with mutations in A-box-1 and A-box-2, indicating their importance in supporting transcription (Supplemental Fig. 2D,E). Unexpectedly, mutating the B-box element increased pre-miR-128-2 and mature miR-128 expression relative to the wild-type promoter (Supplemental Fig. 2D,E).

Proteins putatively regulated by miR-128-2 that may contribute to the ALL phenotype have not been identified. We therefore analyzed TargetScan4.1 (Lewis et al. 2005; Grimson et al. 2007) for predicted miR-128-2 targets that may be relevant to ALL. This program predicts, among others, Huntingtin interacting protein-1 (Hip-1) as a target. Hip-1 mRNA contains an 8mer miR-128-2 binding site located $\sim 1.8 \mathrm{~Kb}$ from the translation termination site (Fig. $5 \mathrm{~A}, \mathrm{~B})$. Hip-1 overexpression has been found in many primary tumors, and Hip-1 interaction with Hippi induces apoptosis through caspase-8 activation (for review, see Gervais et al. 2002; Hyun and Ross 2004). To test whether Hip-1 could be targeted by miR-128-2, we cloned the $3^{\prime}$ UTR of Hip-1 mRNA downstream from the Renilla luciferase reporter in psiCHECK-2 (PS-Hip-1) (Fig. 5C). Relative to the U6miGFP control, U6-miR-128-2 significantly reduced Renilla luciferase reporter activity (40\% knockdown) (Fig. 5D). We extended these studies to test if miR-128-2 could inhibit expression of endogenously expressed Hip-1. Cells transfected with U6-miR-128-2 had significantly reduced levels of Hip-1 protein as assessed by Western blot (Fig. 5E,F).

\section{DISCUSSION}

Our knowledge of miRNA biology has greatly expanded during the last few years, and recent work has begun to clarify our understanding of the transcriptional regulation of miRNA expression. Several reports have used bioinformatic strategies to predict miRNA promoters based on mapping DNA features observed in other known promoters, or by identifying DNA sequences conserved between species (Saini et al. 2007; Zhou et al. 2007; Fujita and Iba 2008). Because intronic miRNAs were generally thought to be transcribed as result of the host gene transcription, initial promoter studies examined mainly intergenic miRNAs. In this work, we extensively analyzed sequences surrounding currently known intronic miRNAs for possible promoter sequences using several criteria. Our data predict that $\sim 35 \%$ of intronic miRNAs can be transcribed from Pol II or Pol III intron-resident promoters, independent of the host gene promoter.

While this work was in progress, two reports using alternative strategies to predict miRNAs promoters were published. These studies used ChIP-on-chip to assess histone modifications, or ChIP-on-chip combined with nucleosome patterning to assess promoter signatures of intergenic and intronic miRNAs (Ozsolak et al. 2008; Wang et al. 2009).
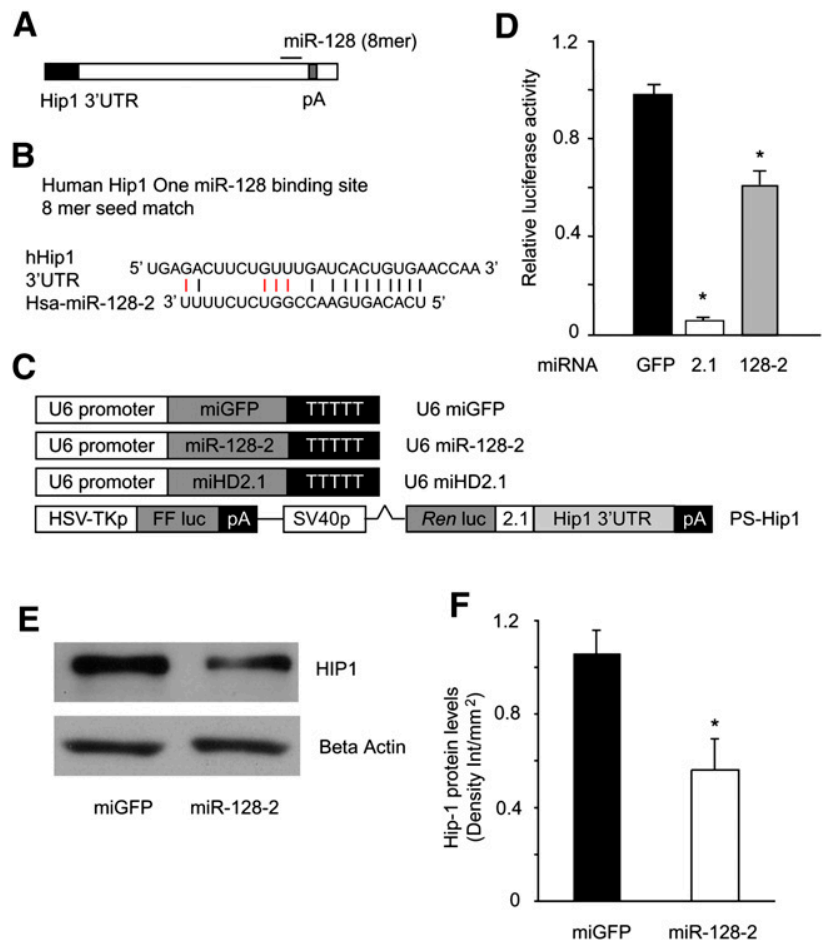

FIGURE 5. Hip-1 is an mRNA target of miR-128-2. (A) Cartoon depicting location of the miR-128-2 binding site in the 3'UTRs of Hip1 mRNA, as predicted and annotated by TargetScan4.1. (B) Predicted binding of miR-128-2 sequence with the Hipl 3 'UTR binding site. $(C)$ Diagram of miRNA expression vectors and Renilla luciferase reporters. U6-miGFP, U6-miHD2.1, and U6-miR-128-2 refer to Pol III expression vectors with the U6 promoter driving the expression of an artificial miRNA targeting eGFP, a miRNA harboring siRNA sequences targeting Huntingtin mRNA, or pre-miR-128-2. PSHip1 is a luciferase reporter construct harboring the full-length $3^{\prime}$ UTR of Hip-1, as well as the perfect match target sequence for miHD2.1. (D) Luciferase activity of protein lysates after cotransfection of HEK293 cells with luciferase reporter constructs for Hip1 3'UTR $(0.05 \mu \mathrm{g})$ and U6-miGFP, U6-miHD2.1, or U6-miR-128b $(0.1 \mu \mathrm{g})$. Data are mean \pm SEM. $\left({ }^{*}\right) P<0.05, n=4$. (E) Representative Western blot of HEK293 cell lysate following transfection with U6 miGFP or U6 miR-128-2. $\beta$-actin was used as a protein-loading control. $(F)$ Densitometry of westerns from three independent experiments; miGFP, $1.1 \pm 0.09$; miR128-2, $\left.0.6 \pm 0.013 .{ }^{*}\right) P<0.05$, $n=3$. Units are density of intensity $/ \mathrm{mm}^{2}$.

Both studies found many intronic miRNAs that are putatively expressed from upstream regulatory elements independent of the host gene. Thus, their reports, together with our work, support the concept that intronic miRNAs can be locally expressed. Independent expression from intronic promoters could be one molecular mechanism to explain why host gene and miRNA expression are not always correlative (Baskerville and Bartel 2005; Liang et al. 2007).

While our datasets largely overlap with the Ozsolak study (Ozsolak et al. 2008), there are several noted differences. One is when we consider the catalog of intronic miRNAs described by Ozsolak et al. (2008). They report that 38 of 95 intronic miRNAs are transcribed from their own promoter, and the remaining 57 from their host gene. Of the 38 
intronic miRNAs with intronic-promoter activity predicted in their work, 25 met our criteria for an intronic miRNA. Examples of miRNAs that did not fit our criteria as an intronic miRNA include miR-564 and miR-632. In these cases, the pre-miRNA mapped upstream of the host gene TSS, or just the $3^{\prime}$ region of the predicted miRNA overlapped with the $5^{\prime}$ end of the host gene primary transcript. These miRNAs, in fact, may have independent promoters but they reside outside of our scanned region. Other examples of miRNAs not included in our assessment are those located on the strand opposite the host gene (Hsa-let7e, hsa-miR-125a, hsa-miR-99b). Out of the 25 that met our criteria as intronic, for 19 of these we also predicted intronic promoters, and for six we did not. These six discrepant miRNAs are miR-548c, miR-550-1, miR-634, miR-125b-2, miR-340, and miR-339. For four of these miRNAs, we found no bioinformatic evidence for an intronic promoter (miR548c, miR-550-1, miR-634, and miR-125b-2). It will be interesting to confirm if the upstream sequences of these miRNAs possess promoter activity using the methods outlined in our study. For miR-340, the predicted TSS was beyond the $5-\mathrm{kb}$ criterion we used as a cutoff, and for miR339, the TSS was linked to a short host gene-derived transcript.

A second variation of our data set from the study of Ozsolak and colleagues regards the 57 miRNAs they report as having no intronic promoter activity in the cell lines tested. Our work indicates that 20 of these miRNAs should be reconsidered, for each has regulatory elements appropriate for independent transcription, from either Pol II (16 of 20 ) or Pol III (4 of 20). For two of these, miR-590 and miR566 , we experimentally validated promoter activity. These intronic promoters may have escaped their detection due to inactivity in the cell lines examined. It is well established that miRNAs can be regulated in specific tissues or distinct cellular states (Avnit-Sagi et al. 2009; Lu et al. 2009; Su et al. 2009), and this likely extends to intronic miRNAs.

The notion of intronic promoters driving expression of intronic miRNAs is relatively recent and broadens our understanding of transcriptional regulation of intronic miRNAs. New questions arise regarding the relative contributions of host gene promoter versus intronic resident promoter to miRNA expression levels, and the mechanisms that control the use of the intronic miRNA promoter with respect to the host gene promoter remain to be determined. For those intronic miRNAs predicted to be transcribed by intronic Pol III and Pol II host gene promoters, it will be important to determine what regulates the occupancy by these two different polymerases, and to determine the contribution of each polymerase to the overall miRNA levels in vivo. It will also be interesting to know if there is any competition in polymerase occupancy.

It is conceivable that different post-transcriptional regulatory mechanisms control miRNA processing, depending on whether the transcript originated from the host gene or an intronic promoter. Interestingly, antisense transcripts have been mapped to intronic miRNAs, suggesting another possible mechanism for regulation of their expression (Stark et al. 2008). This could occur by cotranscription interference or by formation of RNA/RNA duplexes of the complementary transcripts.

Abnormal expression of miRNAs can be associated with disease development (Inomata et al. 2009; Sun et al. 2009). Whether this is disease modifying in a positive or negative way remains to be determined. In the case of Pol III transcription, which can be induced by stress, altered expression could either exacerbate disease phenotypes, or protect the cell. The relative contributions of miRNAs with noted host gene and intronic-resident expression may also vary in disease states. Mir-128-2 is a case in point: Both Ozsolak and colleagues and our work show by ChIP that this miRNA may be expressed from two different promoters, and more interestingly, two different types of promoters. To our knowledge, these are the first descriptions of miRNA sequences being transcribed by two different polymerases. The overexpression of miR-128-2 and its discordant expression with ARPP21 in ALL patients may arise from p53 inactivation, which is common in ALL (Agirre et al. 2003); p53 represses Pol III transcription (Cairns and White 1998; Crighton et al. 2003). Thus, in ALL, p53 inactivation may derepress the intronic promoter and contribute to elevated miR-128-2 levels. This, in turn, could contribute to the ALL phenotype by reducing the expression of Hip-1, at a minimum.

In summary, our analyses, along with additional recent reports (Ozsolak et al. 2008; Wang et al. 2009), indicate that miRNA expression, whether intronic or intergenic, may be complex and varied among tissues, cell types, and disease states.

\section{MATERIALS AND METHODS}

\section{Cell lines and primary neuronal cell cultures}

HEK293 and CRL-1873 cell lines were obtained from ATCC and cultured under conditions provided by the manufacturer. Primary neuronal cell cultures were obtained from time-mated $\mathrm{C} 57 \mathrm{Bl} / 6$ mice (day of plug E0-E0.5). At E17-P0, pregnant mice were deeply anesthetized with Isofluorane (Phoenix Pharmaceutical), sacrificed by cervical dislocation, and the embryos were removed. After brains were dissected and the meninges separated, the motor cortex was isolated, minced with a scalpel blade, and incubated in HBSS-Ca2+/Mg2+ free solution (Invitrogen no. 14175-095) supplemented with papain (2 mg/mL, Sigma P-4762), Pen/Strep $1 \%$, and DNase I $(1 \mathrm{mg} / \mathrm{mL}$, Sigma DN-25) for $\sim 10-15 \mathrm{~min}$ at room temperature. Tissue was rinsed twice in Leibovitz's media (L-15, Invitrogen) and resuspended in $2 \mathrm{~mL}$ of neurobasal/ $10 \%$ FBS medium (Invitrogen). A homogeneous cell suspension was obtained by passing the cells several times through a cotton plugged Pasteur pipette, followed by a fire polished cotton plugged Pasteur pipette. After the dissociation procedure, cells were counted, and a total of 750,000 cells/well were plated onto 
a 24-well plate coated with poly-D-lysine (Sigma). Then, $1 \mathrm{~h}$ later the medium was replaced with neurobasal/B27 medium (Invitrogen). The next day, cells were incubated with BDNF $(50 \mathrm{ng} / \mathrm{mL})$ (Calbiochem), and at the indicated times cells were rinsed with PBS and lysed with $500 \mu \mathrm{L}$ of TRIzol (Invitrogen) for further RNA purification.

\section{Vector construction}

Intronic sequences containing miRNAs were amplified from HEK293 genomic DNA by PCR using Expand HiFi Taq polymerase (Roche), then cloned into pCR2.1-TOPO (Invitrogen) and sequenced. A SV40pA sequence was cloned downstream from the intronic miRNA sequence of predicted intronic miRNAs transcribed by Pol II promoters. Human pre-miRNA sequences of miR126 and miR-208b were obtained by primer extension of overlapping DNA-tailed oligonucleotides and cloned into a pCR2.1TOPO (Invitrogen) and sequenced. A SV40pA sequence was cloned downstream from the pre-miRNA sequence. Pol III expression cassettes containing the U6 promoter, miGFP (U6-miGFP), or miHD2.1 (U6-miHD2.1) sequences and Pol III terminator are described in Boudreau et al. (2008). Mouse pre-miR-128-2 sequence was obtained by polymerase extension of overlapping DNAtailed oligonucleotides (IDT) using Taq polymerase (Biolase), digested with XhoI/SpeI, and cloned into a Pol III expression cassette vector, as described by Boudreau et al. (2008). Vector expressing miHD2.1 under the control of miR-128-2 promoter was obtained by substitution of U6 promoter (ApaI/XhoI fragment) from U6-miHD2.1 with a tailed PCR product including the miR128-2 5' sequence. The Pol II and Pol III eGFP reporter constructs were made inserting a PCR-tailed product that includes the promoter sequence (CMV-Pol II, U6-Pol III, pAL Pol III, or 5 'sequence of $128 \mathrm{~b}$ ), a scrambled sequence, and a polythymidine stretch ( 8 T's) (NheI/XhoI fragment) into a Ad5-MCS-eGFP shuttle vector. Amplicons were obtained with Pfu Turbo polymerase (Stratagene), cloned in pCRBluntII-TOPO, sequenced, and positive clones digested with NheI/XhoI restriction sites. MiR-128-2 promoter mutants were cloned by primer extension in $50-\mu \mathrm{L}$ reactions using $0.5 \mathrm{U}$ Taq polymerase (Biolase), $0.2 \mu \mathrm{M}$ each primer, $1.5 \mathrm{mM}$ $\mathrm{MgCl}_{2}, 0.2 \mathrm{mM} \mathrm{dNTP}$, and $1 \mathrm{x}$ Biolase buffer, and using cycling parameters $\left(5 \mathrm{~min}\right.$ at $95^{\circ} \mathrm{C}, 2 \mathrm{~min}$ at $62^{\circ} \mathrm{C}, 15 \mathrm{~min}$ at $72^{\circ} \mathrm{C}$, hold $\left.4^{\circ} \mathrm{C}\right)$. Resultant amplicons were resolved by $2 \%$ agarose gel electrophoresis, DNA was gel extracted, cloned into pCR2.1-TOPO, and sequenced. Total RNA from C57Bl/6 striata was used to obtain a cDNA library with random hexamers or oligo dT primers. Hip1 3'UTR sequences were amplified by PCR with tailed primers using Expand Taq HiFi polymerase (Roche), then cloned into pCR2.1TOPO, and sequenced. Positive sequences were cloned into psiCHECK-2 (Promega), modified to contain a complementary sequence for miHD2.1 and a small multicloning site in the $3^{\prime} \mathrm{UTR}$ of the Renilla luciferase.

\section{In vitro luciferase assays}

HEK293 cells were cultured in DMEM (10\% FBS (v/v), 1\% Pen/ Strep $(\mathrm{v} / \mathrm{v})$, and $1 \%$ L-Glutamine $(\mathrm{v} / \mathrm{v})$ in a 24 -well plate. At $70 \%-$ $80 \%$ confluence, cells were cotransfected with miRNA-expressing plasmid and 3'UTR-luciferase reporter plasmids at indicated amounts in Figure 5 (Lipofectamine 2000, Invitrogen). At $24 \mathrm{~h}$, cells were rinsed with ice-cold PBS and Renilla and Firerfly luciferase activities were assessed using the Dual-Luciferase Reporter Assay System (Promega) according to the manufacturer's instructions, using $20 \mu \mathrm{L}$ of substrate. Luminescent readouts were obtained with a Monolight 3010 luminometer (Pharmigen). Relative light units were calculated as the quotient of Renilla/Firefly relative light units and results expressed relative to a control miRNA.

\section{Western blot analysis}

HEK293 cells were transfected with miRNA-expressing plasmids or eGFP reporter promoter vectors as indicated. At $36-48 \mathrm{~h}$, cells were rinsed once with ice-cold PBS and lysed with RIPA lysis buffer $(150 \mathrm{mM} \mathrm{NaCl}, 10 \mathrm{mM}$ Tris at $\mathrm{pH} 7.4,0.1 \%$ SDS, $1 \%$ Triton X-100, 1\% Deoxicholate, 5 mM EDTA) supplemented with DNase I $(1 \mu \mathrm{L} / \mathrm{mL}$, Fermentas) and mini Complete Protease inhibitors (Roche). Protein concentration was determined by the Bradford-Lowry method (Bio-Rad) and $20 \mu \mathrm{g}$ of protein loaded on $8 \%$ SDS/PAGE gels. Proteins were transferred onto PVDF membranes and incubated with anti-HIP-1 (1:1000, BD Bioscience), anti-eGFP (1:5000, Molecular Probes), or anti $\beta$-actin (1:40000, Sigma) antibodies, followed by horseradish peroxidasecoupled antibodies (1:10,000-1:50,000; Jackson ImmunoResearch). Blots were developed with ECL-Plus reagents (Amersham Pharmacia). Silencing efficacy was determined by densitometry ( $n=3$ independent experiments) of protein levels relative to $\beta$-actin with the Epichem II Darkroom system (95-0310-01, UVP) and Lab Works 4.0 image analysis software.

\section{RNA extraction and qPCR analysis}

Total RNA isolation was extracted using TRIzol (Life Technologies) according to the manufacturer's protocol, with the exception of two washes with cold $70 \%$ ethanol. RNA samples were quantified by spectrophotometry, and $1.0 \mu \mathrm{g}$ of total RNA treated for $1.5 \mathrm{~h}$ with DNase I to remove genomic or plasmid contamination (DNA-free kit, Ambion) and subsequently cDNAs generated from $200 \mathrm{ng}$ of total RNA with a specific RT primer for premiR-128 (ThermoScript RT-PCR system, Invitrogen) or random hexamers (TaqMan RT reagents, Applied Biosystems). Relative gene expression was assessed using TaqMan primer/probe set specifics for pre-miR-128-2 (IDT), mature miR-128, RNU48, 18S, and long transcripts of Arpp-21 (TaqMan 2X universal Master mix, ABI PRISM 7900HT Sequence Detection System; Applied Biosystems). Relative gene expression was determined using the relative standard curve method or ddCt method as indicated.

\section{Chromatin immunoprecipitation (ChIP)}

ChIP on CRL-1873 cells was done as described by Borchert et al. (2006) with few modifications. Briefly, two aliquots of CRL-1783 cells with a density of $3-4 \cdot 106$ cells $/ \mathrm{mL}$ were fixed with $1 \%$ formaldehyde for $15 \mathrm{~min}$, followed by a 5-min $125 \mathrm{mM}$ glycine quench. Cells were centrifuged $\left(1700 \mathrm{~g}\right.$ for $10 \mathrm{~min}$ at $\left.4^{\circ} \mathrm{C}\right)$ and rinsed with $2 \mathrm{~mL}$ of ice-cold PBS supplemented with protease inhibitors. Pellets were resuspended in $600 \mu \mathrm{L}$ of SDS sonication buffer (1\% SDS, $10 \mathrm{mM}$ EDTA, $50 \mathrm{mM}$ Tris- $\mathrm{HCl}$ at $\mathrm{pH} 8$, + proteasome inhibitors). Sonication conditions were determined empirically to cleave genomic DNA to $300-\mathrm{bp}-1-\mathrm{Kb}$ fragments (six times, $20 \mathrm{sec}$ each pulse). Cross-linked DNA/histones were diluted $1 / 10$ in ChIP dilution buffer $(0.01 \%$ SDS, $1.1 \%$ Triton-X 
100, $1.2 \mathrm{mM}$ EDTA, $16.7 \mathrm{mM}$ Tris- $\mathrm{HCl}$ at $\mathrm{pH} 8,167 \mathrm{mM} \mathrm{NaCl}$ and protease inhibitors) and precleared with $40 \mu \mathrm{L}$ of Protein G/DNA salmon sperm (Upstate Biotech) for $1 \mathrm{~h}$ at $4^{\circ} \mathrm{C}$. Approximately $1 / 10$ th of the sample was removed as input control, while the remainder of the sample was divided in equal volumes and incubated $\mathrm{o} / \mathrm{n}$ at $4^{\circ} \mathrm{C}$ with $1 \mu \mathrm{L}$ of specific antibodies against RNA Pol III (obtained from Dr. William Henry, Michigan State University) (Hirsch et al. 2004), RNA Pol II (Upstate Biotech), mouse IgG control (Upstate Biotech) antibodies, and no antibody control. Chromatin/antibody complexes were collected using $65 \mu \mathrm{L}$ of protein G/DNA salmon sperm $\left(2 \mathrm{~h}\right.$ at $4^{\circ} \mathrm{C}$, Upstate Biotech) and rinsed for $5 \mathrm{~min}$ at $4^{\circ} \mathrm{C}$ sequentially in ChIP buffer $1(0.1 \%$ SDS, $1 \%$ Triton $\mathrm{X}-100,2 \mathrm{mM}$ EDTA, $20 \mathrm{mM}$ Tris- $\mathrm{HCl}$ at $\mathrm{pH} 8$, $150 \mathrm{mM} \mathrm{NaCl})$, ChIP buffer $2(0.1 \%$ SDS, $1 \%$ Triton X-100, $2 \mathrm{mM}$ EDTA, $20 \mathrm{mM}$ Tris- $\mathrm{HCl}$ at $\mathrm{pH} 8,500 \mathrm{mM} \mathrm{NaCl}$ ), ChiP buffer $3(0.25 \mathrm{M} \mathrm{LiCl}, 0.5 \% \mathrm{NP}-40,1 \mathrm{mM}$ EDTA, $10 \mathrm{mM}$ Tris- $\mathrm{HCl}$ at $\mathrm{pH} 8,0.5 \% \mathrm{Na}$ Deoxycholate), and two washes of TE $(\mathrm{pH} 8)$. Complexes were eluted with $480 \mu \mathrm{L}$ of $0.1 \mathrm{M}$ NaHCO $3 \%-1 \%$ SDS for $30 \mathrm{~min}$ at room temperature. Protein/DNA cross-links were reversed using $200 \mathrm{mM} \mathrm{NaCl}$ at $65^{\circ} \mathrm{C}$ o/n. Samples were then treated with $4 \mu \mathrm{L}$ of $10 \mathrm{mg} / \mathrm{mL}$ proteinase $\mathrm{K}, 10 \mu \mathrm{L}$ of $0.5 \mathrm{M}$ EDTA, and $20 \mu \mathrm{L}$ of Tris-HCl ( $\mathrm{pH}$ 6.5) $1 \mathrm{M}$ for $2 \mathrm{~h}$ at $45^{\circ} \mathrm{C}$. DNA was purified with phenol/chloroform, precipitated with ethanol, and resuspended in $50 \mu \mathrm{L}$ of TE buffer. PCR analysis was performed with $5 \mu \mathrm{L}$ of each immunoprecipitated sample or input chromatin. The primers used to amplify the genes were:

U6 forward ( $5^{\prime}$-GTACAAAATACGTGACGTAGAAAG-3');

U6 reverse ( $5^{\prime}$-GGTGTTTCGTCCTTTCCAC-3');

U2 forward ( $5^{\prime}$-AGGGCGTCAATAGCGCTGTGG-3'); U2 reverse ( $5^{\prime}$-TGCGCTCGCCTTCGCGCCCGCCG-3');

128-2 forward (5'-TGCTTCCTCTGTTCTTAAGGCTAGGG-3'); and

128-2 reverse (5' -CATGTGGCCATCATGAAAGTGAAC-3').

PCR products were separated in a $2 \%$ agarose gel, stained with ethidium bromide. MiR-128-2 enrichment was quantified by SyBrGreen qPCR. Fold enrichment of target sequence was calculated using the $\mathrm{ddCt}$, with normalization to input and expressed relative to No antibody control IgG.

\section{Statistic analysis}

Student's $t$-test implemented with Excel program was used for all studies. In all statistical analysis, $P<0.05$ was considered significant.

\section{SUPPLEMENTAL MATERIAL}

Supplemental material can be found at http://www.rnajournal.org.

\section{ACKNOWLEDGMENTS}

We thank members of the Davidson and Xing laboratory for helpful discussions, Dr. Stein for critical review of the manuscript, Jesse Riordan and Alexey Sohnev for help with cloning, and Dr. William Henry for advice and discussions and for providing the Pol III antibody. This work was supported by the NIH (DA025132, NS50210, and HD44093) and the Roy J Carver Trust.

Received May 11, 2009; accepted November 13, 2009.

\section{REFERENCES}

Agirre X, Novo FJ, Calasanz MJ, Larrayoz MJ, Lahortiga I, Valganon M, Garcia-Delgado M, Vizmanos JL. 2003. TP53 is frequently altered by methylation, mutation, and/or deletion in acute lymphoblastic leukaemia. Mol Carcinog 38: 201-208.

Avnit-Sagi T, Kantorovich L, Kredo-Russo S, Hornstein E, Walker MD. 2009. The promoter of the pri-miR-375 gene directs expression selectively to the endocrine pancreas. PLoS One 4: e5033. doi: 10.1371/journal.pone.0005033.

Bagga S, Bracht J, Hunter S, Massirer K, Holtz J, Eachus R, Pasquinelli AE. 2005. Regulation by let-7 and lin-4 miRNAs results in target mRNA degradation. Cell 122: 553-563.

Baskerville S, Bartel DP. 2005. Microarray profiling of microRNAs reveals frequent coexpression with neighboring miRNAs and host genes. RNA 11: 241-247.

Berezikov E, Chung WJ, Willis J, Cuppen E, Lai EC. 2007. Mammalian mirtron genes. Mol Cell 28: 328-336.

Bernstein E, Caudy AA, Hammond SM, Hannon GJ. 2001. Role for a bidentate ribonuclease in the initiation step of RNA interference. Nature 409: 363-366.

Bogenhagen DF, Brown DD. 1981. Nucleotide sequences in Xenopus 5S DNA required for transcription termination. Cell 24: 261-270.

Bohnsack MT, Czaplinski K, Gorlich D. 2004. Exportin 5 is a RanGTP-dependent dsRNA-binding protein that mediates nuclear export of pre-miRNAs. RNA 10: 185-191.

Borchert GM, Lanier W, Davidson BL. 2006. RNA polymerase III transcribes human microRNAs. Nat Struct Mol Biol 13: 10971101.

Boudreau RL, Monteys AM, Davidson BL. 2008. Minimizing variables among hairpin-based RNAi vectors reveals the potency of shRNAs. RNA 14: 1834-1844.

Cairns CA, White RJ. 1998. p53 is a general repressor of RNA polymerase III transcription. EMBO J 17: 3112-3123.

Crighton D, Woiwode A, Zhang C, Mandavia N, Morton JP, Warnock LJ, Milner J, White RJ, Johnson DL. 2003. p53 represses RNA polymerase III transcription by targeting TBP and inhibiting promoter occupancy by TFIIIB. EMBO J 22: 2810-2820.

Down TA, Hubbard TJ. 2002. Computational detection and location of transcription start sites in mammalian genomic DNA. Genome Res 12: 458-461.

Fujita S, Iba H. 2008. Putative promoter regions of miRNA genes involved in evolutionarily conserved regulatory systems among vertebrates. Bioinformatics 24: 303-308.

Gaeta BA, Sharp SJ, Stewart TS. 1990. Saturation mutagenesis of the Drosophila tRNA ${ }^{\mathrm{Arg}}$ gene B-Box intragenic promoter element: Requirements for transcription activation and stable complex formation. Nucleic Acids Res 18: 1541-1548.

Geiduschek EP, Tocchini-Valentini GP. 1988. Transcription by RNA polymerase III. Annu Rev Biochem 57: 873-914.

Gervais FG, Singaraja R, Xanthoudakis S, Gutekunst CA, Leavitt BR, Metzler M, Hackam AS, Tam J, Vaillancourt JP, Houtzager V, et al. 2002. Recruitment and activation of caspase- 8 by the Huntingtin-interacting protein Hip-1 and a novel partner Hippi. Nat Cell Biol 4: 95-105.

Gregory RI, Chendrimada TP, Cooch N, Shiekhattar R. 2005. Human RISC couples microRNA biogenesis and post-transcriptional gene silencing. Cell 123: 631-640.

Griffiths-Jones S. 2007. Annotating noncoding RNA genes. Annu Rev Genomics Hum Genet 8: 279-298.

Griffiths-Jones S, Saini HK, van Dongen S, Enright AJ. 2008. miRBase: Tools for microRNA genomics. Nucleic Acids Res 36: D154-D158.

Grimm D, Streetz KL, Jopling CL, Storm TA, Pandey K, Davis CR, Marion P, Salazar F, Kay MA. 2006. Fatality in mice due to oversaturation of cellular microRNA/short hairpin RNA pathways. Nature 441: 537-541.

Grimson A, Farh KK, Johnston WK, Garrett-Engele P, Lim LP, Bartel DP. 2007. MicroRNA targeting specificity in mammals: Determinants beyond seed pairing. Mol Cell 27: 91-105. 
Gunnery S, Ma Y, Mathews MB. 1999. Termination sequence requirements vary among genes transcribed by RNA polymerase III. J Mol Biol 286: 745-757.

Hirsch HA, Jawdekar GW, Lee KA, Gu L, Henry RW. 2004. Distinct mechanisms for repression of RNA polymerase III transcription by the retinoblastoma tumor suppressor protein. Mol Cell Biol 24: 5989-5999.

Hutvagner G, McLachlan J, Pasquinelli AE, Balint E, Tuschl T, Zamore PD. 2001. A cellular function for the RNA-interference enzyme Dicer in the maturation of the let-7 small temporal RNA. Science 293: 834-838.

Hyun TS, Ross TS. 2004. HIP1: Trafficking roles and regulation of tumorigenesis. Trends Mol Med 10: 194-199.

Inomata $\mathrm{M}$, Tagawa $\mathrm{H}$, Guo $\mathrm{YM}$, Kameoka $\mathrm{Y}$, Takahashi $\mathrm{N}$, Sawada K. 2009. MicroRNA-17-92 down-regulates expression of distinct targets in different B-cell lymphoma subtypes. Blood 113: 396-402.

Ivkovic S, Ehrlich ME. 1999. Expression of the striatal DARPP-32/ ARPP-21 phenotype in GABAergic neurons requires neurotrophins in vivo and in vitro. J Neurosci 19: 5409-5419.

Jiang H, Wong WH. 2008. SeqMap: Mapping massive amount of oligonucleotides to the genome. Bioinformatics 24: 2395-2396.

Kim YK, Kim VN. 2007. Processing of intronic microRNAs. EMBO J 26: $775-783$.

Lai EC. 2002. MicroRNAs are complementary to $3^{\prime}$ UTR sequence motifs that mediate negative post-transcriptional regulation. Nat Genet 30: 363-364.

Larsen F, Gundersen G, Lopez R, Prydz H. 1992. CpG islands as gene markers in the human genome. Genomics 13: 1095-1107.

Lee JY, Evans CF, Engelke DR. 1991. Expression of RNase P RNA in Saccharomyces cerevisiae is controlled by an unusual RNA polymerase III promoter. Proc Natl Acad Sci 88: 6986-6990.

Lee Y, Jeon K, Lee JT, Kim S, Kim VN. 2002. MicroRNA maturation: Stepwise processing and subcellular localization. EMBO $J$ 21: 4663-4670.

Lee Y, Ahn C, Han J, Choi H, Kim J, Yim J, Lee J, Provost P, Radmark O, Kim S, et al. 2003. The nuclear RNase III Drosha initiates microRNA processing. Nature 425: 415-419.

Lewis BP, Burge CB, Bartel DP. 2005. Conserved seed pairing, often flanked by adenosines, indicates that thousands of human genes are microRNA targets. Cell 120: 15-20.

Liang Y, Ridzon D, Wong L, Chen C. 2007. Characterization of microRNA expression profiles in normal human tissues. BMC Genomics 8: 166. doi: 10.1186/1471-2164-8-166.

Lu TX, Munitz A, Rothenberg ME. 2009. MicroRNA-21 is upregulated in allergic airway inflammation and regulates IL-12p35 expression. J Immunol 182: 4994-5002.

Lujambio A, Esteller M. 2007. CpG island hypermethylation of tumor suppressor microRNAs in human cancer. Cell Cycle 6: $1455-1459$.

Lund E, Guttinger S, Calado A, Dahlberg JE, Kutay U. 2004. Nuclear export of microRNA precursors. Science 303: 95-98.

Mi S, Lu J, Sun M, Li Z, Zhang H, Neilly MB, Wang Y, Qian Z, Jin J, Zhang Y, et al. 2007. MicroRNA expression signatures accurately discriminate acute lymphoblastic leukemia from acute myeloid leukemia. Proc Natl Acad Sci 104: 19971-19976.

Morlando M, Ballarino M, Gromak N, Pagano F, Bozzoni I, Proudfoot NJ. 2008. Primary microRNA transcripts are processed co-transcriptionally. Nat Struct Mol Biol 15: 902-909.

Naykova TM, Kondrakhin YV, Rogozin IB, Voevoda MI, Yudin NS, Romaschenko AG. 2003. Concerted changes in the nucleotide sequences of the intragenic promoter regions of eukaryotic genes for tRNAs of all specificities. J Mol Evol 57: 520-532.

Okamura K, Hagen JW, Duan H, Tyler DM, Lai EC. 2007. The mirtron pathway generates microRNA-class regulatory RNAs in Drosophila. Cell 130: 89-100.

Ozsolak F, Poling LL, Wang Z, Liu H, Liu XS, Roeder RG, Zhang X, Song JS, Fisher DE. 2008. Chromatin structure analyses identify miRNA promoters. Genes \& Dev 22: 3172-3183.

Park JS, Kunkel GR. 1995. Both RNA polymerase III and RNA polymerase II accurately initiate transcription from a human U6 promoter in vitro. Biochem Biophys Res Commun 214: 934-940.

Pawlicki JM, Steitz JA. 2008. Primary microRNA transcript retention at sites of transcription leads to enhanced microRNA production. J Cell Biol 182: 61-76.

Ruby JG, Jan CH, Bartel DP. 2007. Intronic microRNA precursors that bypass Drosha processing. Nature 448: 83-86.

Saini HK, Enright AJ, Griffiths-Jones S. 2008. Annotation of mammalian primary microRNAs. BMC Genomics 9: 564. doi: 10.1186/ 1471-2164-9-564.

Saini HK, Griffiths-Jones S, Enright AJ. 2007. Genomic analysis of human microRNA transcripts. Proc Natl Acad Sci 104: 1771917724.

Sekido Y, Bader S, Latif F, Chen JY, Duh FM, Wei MH, Albanesi JP, Lee CC, Lerman MI, Minna JD. 1996. Human semaphorins A(V) and IV reside in the 3 p21.3 small cell lung cancer deletion region and demonstrate distinct expression patterns. Proc Natl Acad Sci 93: 4120-4125.

Stark A, Bushati N, Jan CH, Kheradpour P, Hodges E, Brennecke J, Bartel DP, Cohen SM, Kellis M. 2008. A single Hox locus in Drosophila produces functional microRNAs from opposite DNA strands. Genes \& Dev 22: 8-13.

Stewart TS, Soll D, Sharp S. 1985. Point mutations in the $5^{\prime}$ ICR and anticodon region of a Drosophila tRNA ${ }^{\mathrm{Arg}}$ gene decrease in vitro transcription. Nucleic Acids Res 13: 435-447.

Su H, Yang JR, Xu T, Huang J, Xu L, Yuan Y, Zhuang SM. 2009. MicroRNA-101, down-regulated in hepatocellular carcinoma, promotes apoptosis and suppresses tumorigenicity. Cancer Res 69: $1135-1142$.

Sun T, Wang Q, Balk S, Brown M, Lee GS, Kantoff P. 2009. The role of microRNA-221 and microRNA-222 in androgen-independent prostate cancer cell lines. Cancer Res 69: 3356-3363.

Wang X, Xuan Z, Zhao X, Li Y, Zhang MQ. 2009. High-resolution human core-promoter prediction with CoreBoost_HM. Genome Res 19: 266-275.

Zhou X, Ruan J, Wang G, Zhang W. 2007. Characterization and identification of microRNA core promoters in four model species. PLoS Comput Biol 3: e37. doi: 10.1371/journal.pcbi.0030037. 

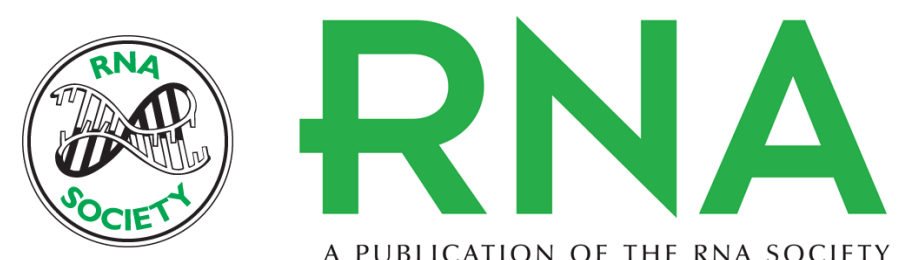

A PUBLICATION OF THE RNA SOCIETY

\section{Structure and activity of putative intronic miRNA promoters}

Alex Mas Monteys, Ryan M. Spengler, Ji Wan, et al.

RNA 2010 16: 495-505 originally published online January 14, 2010

Access the most recent version at doi:10.1261/rna.1731910

Supplemental

Material

References

Open Access

License Freely available online through the RNA Open Access option.

Freely available online through the RNA Open Access option.
http://rnajournal.cshlp.org/content/suppl/2010/01/07/rna.1731910.DC1

This article cites 57 articles, 23 of which can be accessed free at: http://rnajournal.cshlp.org/content/16/3/495.full.html\#ref-list-1

Receive free email alerts when new articles cite this article - sign up in the box at the top right corner of the article or click here. 